University of Nebraska - Lincoln

DigitalCommons@University of Nebraska - Lincoln

Papers in the Earth and Atmospheric Sciences

Earth and Atmospheric Sciences, Department

September 2003

\title{
Sedimentary aggregates in the Peoria Loess of Nebraska, USA
}

Joseph A. Mason

University of Nebraska-Lincoln, jmason2@unl.edu

Peter M. Jacobs

University of Wisconsin-Whitewater, Whitewater, WI

Richard S. B. Greene

Environment and Society, ANU, Canberra, 0200, ACT, Australia

Follow this and additional works at: https://digitalcommons.unl.edu/geosciencefacpub

Part of the Earth Sciences Commons

Mason, Joseph A.; Jacobs, Peter M.; and Greene, Richard S. B., "Sedimentary aggregates in the Peoria Loess of Nebraska, USA" (2003). Papers in the Earth and Atmospheric Sciences. 13.

https://digitalcommons.unl.edu/geosciencefacpub/13

This Article is brought to you for free and open access by the Earth and Atmospheric Sciences, Department of at DigitalCommons@University of Nebraska - Lincoln. It has been accepted for inclusion in Papers in the Earth and Atmospheric Sciences by an authorized administrator of DigitalCommons@University of Nebraska - Lincoln. 


\title{
Sedimentary aggregates in the Peoria Loess of Nebraska, USA
}

\author{
Joseph A. Mason ${ }^{\mathrm{a}, *}$, Peter M. Jacobs ${ }^{\mathrm{b}}$, \\ Richard S.B. Greene $^{c}$, W.D. Nettleton ${ }^{d}$ \\ ${ }^{a}$ Conservation and Survey Division and Department of Geosciences, University of Nebraska-Lincoln, \\ 113 Nebraska Hall, Lincoln, NE 68588-0517, USA \\ ${ }^{\mathrm{b}}$ Department of Geography and Geology, University of Wisconsin-Whitewater, 800 W. Main Street, \\ Whitewater, WI 53190, USA \\ ${ }^{\mathrm{c}}$ School of Resources, Environment and Society, ANU, Canberra, 0200, ACT, Australia \\ ${ }^{\mathrm{d}}$ USDA, NRCS, NSSC 100 Centennial Mall North, Lincoln, NE 68508, USA
}

Received 3 April 2002; accepted 28 March 2003

\begin{abstract}
Loess grain size data used to infer transport direction or wind strength are generally derived from vigorously disaggregated samples. However, these data may not adequately represent the effective particle size distribution during loess transport, if the transported dust contained aggregates of finegrained material. Thin sections of minimally altered $\mathrm{C}$ and $\mathrm{BC}$ horizons in the late Pleistocene Peoria Loess of Nebraska, USA, indicate the presence of aggregates with diameters of 30-1000 $\mu \mathrm{m}$. The larger aggregates $(>250 \mu \mathrm{m})$ are unlikely to have been transported, and are interpreted as the result of soil faunal activity and other pedogenic processes after deposition. Aggregates smaller than $250 \mu \mathrm{m}$ could have a similar origin, but laser diffraction particle size analysis suggests that many are sedimentary particles. Comparison of minimally and fully dispersed particle size distributions from each sampling site was used to estimate the modal diameter of aggregates. The aggregate modal diameter becomes finer with decreasing loess thickness, representing increasing distance from the source. A similar trend was observed in the modal diameter of fully dispersed particle size distributions, which represents the mode of sand and silt transported as individual grains. We interpret both trends as the result of sorting during transport, supporting the interpretation that many of the aggregates were transported rather than formed in place. Aggregate content appears to increase with distance from the source, explaining a much more rapid downwind increase in clay content than would be expected if clay were transported as particles smaller than $2 \mu \mathrm{m}$ diameter. Although the Peoria Loess of Nebraska contains sedimentary aggregates, many of the coarse silt and sand grains in
\end{abstract}

\footnotetext{
* Corresponding author.

E-mail address: jmason2@unl.edu (J.A. Mason).
} 
this loess were transported as primary particles, were thoroughly exposed to sunlight and are potentially well suited for luminescence dating.

(C) 2003 Elsevier Science B.V. All rights reserved.

Keywords: Loess; Aggregates; Particle size analysis; Laser diffractometry; Luminescence dating; Nebraska

\section{Introduction}

Loess deposits generally lack sedimentary structures indicating transport direction or wind strength, but both can be inferred from the particle size distribution (PSD) (Smith, 1942; Frazee et al., 1970; Mason et al., 1994; Lu et al., 1999; Muhs and Bettis, 2000). This has prompted collection of a large volume of data on the PSD of loess in many areas.

Most published loess PSDs are derived from analyses in which samples are disaggregated, using chemical dispersants and/or ultrasound, often preceded by treatments to remove organic matter and carbonates. It is well known, however, that eolian sediment can be transported as both primary grains (individual rock fragments) and silt- or sand-sized aggregates of primary grains and secondary clay minerals (Chepil and Woodruff, 1963). An extreme case is the parna deposits of Australia, which contain wind-blown sand- or silt-sized aggregates of clay mixed with primary sand and silt grains (Butler, 1956; Bowler, 1973; Dare-Edwards, 1984).

It is clear that the PSD of parna after full dispersion will not accurately represent the state of the sediment during transport, but it is uncertain whether this is a significant problem with the more typical silt-dominated loess. PSD data suggest that loess in the central United States was transported at least in part as primary silt grains, but evidence for transport of aggregates has also been reported. Studies of vigorously dispersed loess PSDs show that coarser silt fractions decrease and finer fractions increase with distance from loess sources independently identified by thickness trends (Smith, 1942; Frazee et al., 1970; Ruhe, 1983; Mason et al., 1994; Muhs and Bettis, 2000). Such effective sorting of primary silt grains along the transport path indicates that many of them were transported as single grains rather than within aggregates. On the other hand, microscopic examination of undispersed samples or thin sections of undisturbed sediment has indicated many coated grains and aggregates in loess from the Missouri River valley and Great Plains regions (Gibbs and Holland, 1960; Brice, 1966; Daniels, 1967). Discrete loess units rich in transported aggregates (or "pellets") have also been reported from other loess regions (Kukla, 1975; Frechen et al., 1999), though not from central North America.

The occurrence of transported aggregates in loess has various implications, even if the aggregates are not so abundant as to confound interpretation of transport direction or wind speed from the PSD of dispersed samples. For example, fine silt and clay bound in aggregates will be deposited much closer to the loess source than individual particles of the same size. Aggregates and coated grains may also affect the results of luminescence dating. Quartz and feldspar grains shielded by coatings or within aggregates may not be effectively bleached by sunlight during transport, a requirement for successful luminescence dating (Frechen et al., 1999; Lian and Huntley, 1999). 
McTainsh et al. (Kiefert et al., 1992; McTainsh et al., 1997a,b) used PSDs of samples "minimally dispersed" in water to approximate the effective size distribution of modern dust during atmospheric transport. The particles included in this "effective size distribution" may include both primary grains and aggregates. More thorough dispersion of modern dust samples containing aggregates can yield different PSDs. Particle size analysis (PSA) before and after vigorous dispersion has also been used to distinguish between the "effective" (aggregated) and "ultimate" (disaggregated, primary grain) PSDs of watertransported eroded soil (Slattery and Burt, 1995; Nicholas and Walling, 1996; Beuselinck et al., 1999). Laser diffraction PSA offers great promise in this area because it produces a high resolution PSD in a single analysis, facilitating comparison of fully and minimally dispersed PSDs to characterize the PSD of aggregates (Beuselinck et al., 1999).

For loess deposits, comparison of the PSD before and after complete dispersion may or may not accurately characterize the extent of aggregation during transport, because of changes in aggregation after deposition. For example, post-depositional wetting could slake transported aggregates, creating a massive structure (Kwaad and Muecher, 1994). Also, new aggregates can develop in near-surface horizons through pedogenic processes (Bullock et al., 1985, pp. 39-49; FitzPatrick, 1993, pp. 118-134).

In this paper, we examine the extent to which wind-transported aggregates can be identified in the late Pleistocene Peoria Loess of Nebraska, USA, and the relative abundance of such aggregates within the deposit. We use laser diffraction PSA and thin sections to address this problem, and compare PSDs of minimally and fully dispersed loess samples. Trends of aggregate modal diameter are examined to determine whether the aggregates become finer with distance from the loess source, as would be expected for sedimentary particles transported as suspended dust (McTainsh, 1999).

\section{Methods and materials}

\subsection{Field sampling and laboratory methods}

The Late Pleistocene Peoria Loess of Nebraska, USA, was deposited approximately $25,000-12,000$ years before present. It is an easily recognized stratigraphic unit that blankets uplands across large parts of the central United States, including the central Great Plains (Schultz and Stout, 1945; Muhs et al., 1999; Mason, 2001). It is unusually coarse in Nebraska, compared to the global range of loess grain size, and in some areas is dominated by very fine sand. Fig. 1 shows sampling sites for this study and the regional pattern of Peoria Loess thickness in Nebraska, based on analysis of more than 600 thickness measurements in geologic test holes (Mason, 2001). The thickness pattern illustrated in Fig. 1 indicates that Peoria Loess was transported from northwest to southeast across most of Nebraska, including all of the sampling sites. It was derived from the unglaciated landscape northwest of the loess deposits, mainly from Tertiary siltstones and stream or lake sediments derived from them (Aleinikoff et al., 1998; Mason, 2001). Sampling sites were selected to form three northwest-southeast transects corresponding to loess thickness gradients (Fig. 1). This set covers wide ranges of Peoria Loess thickness and distance from the inferred loess source. All sampling sites were located on uplands, all but one on 


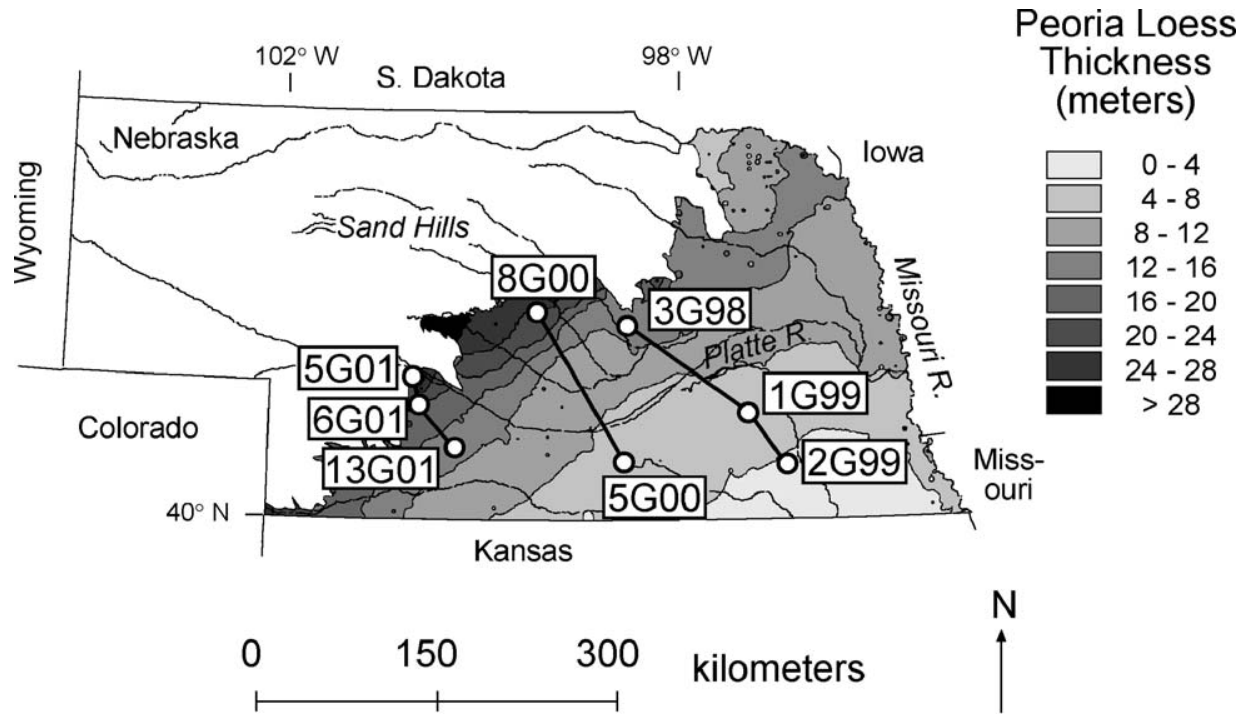

Fig. 1. Location of sampling sites within the state of Nebraska, USA. Thickness of the Peoria Loess on stable upland summits, interpolated from geologic test holes, indicated by gray shading. Northwest of the shaded area, there is little or no identifiable Peoria Loess. See Mason (2001) for details on data sources, interpolation methods, and inferred loess sources. Sampling sites are laid out in three transects from thicker to thinner loess (Western Transect: 5G01, 6G01, 13G01; Central Transect: 8G00, 5G00; Eastern Transect: 3G98, 1G99, 2G99).

nearly level summits (site 5G01 is on the rim of a closed depression). Thus, all samples are assumed to represent primary eolian loess with little or no reworking by slopewash. At some sampling sites, Peoria Loess is overlain by $>1 \mathrm{~m}$ of Holocene Bignell Loess, with the two units separated by a prominent paleosol, the Brady soil (Schultz and Stout, 1945; Johnson and Willey, 2000). At the other sites, the Bignell Loess and Brady soil could be incorporated into the A and B horizons of the modern surface soil (Kuzila, 1995). At each site, either we have a direct measurement of total Peoria Loess thickness, or we can estimate it from nearby boreholes (Mason, 2001).

In our study of aggregates we focused on horizons in Peoria Loess with little macroscopic evidence of pedogenesis. These included massive $\mathrm{C}$ horizons and $\mathrm{BC}$ horizons in which the only evidence of pedogenesis is weak blocky structure, which often extends $>2 \mathrm{~m}$ below the A horizon of the surface soil or Brady soil. We also investigated aggregation in some surface soil A and B horizons to detect any vertical trends resulting from post-depositional pedogenesis. All samples were collected from undisturbed cores obtained with a hydraulic soil coring machine. Little or no compression or other deformation was observed during core collection.

A total of 48 intact 5- or 7-cm diameter core segments, from soil profiles at sites 3G98, 2G99, $5 \mathrm{G} 00$ and $8 \mathrm{G} 00$ (Fig. 1), were selected for thin section preparation. These included numerous $\mathrm{C}$ and $\mathrm{BC}$ horizon samples, along with overlying $\mathrm{A}$ and $\mathrm{B}$ horizons for comparison. After air drying, these samples were sent to Spectrum Petrographics (Winston, OR) where they were vacuum impregnated, then cut and ground to form 30 $\mu \mathrm{m}$ thick sections. 
Aggregation was assessed in 24 samples from $\mathrm{C}$ and minimally altered $\mathrm{BC}$ horizons (three from each of the eight study sites) using PSA after different degrees of dispersion. These representative samples were selected on the basis of a larger set of PSDs available from each site. A further 10 samples were selected from overlying Bt or Bk horizons, but results are only briefly discussed below. The $\mathrm{C}$ and $\mathrm{BC}$ horizon samples were from depths down to $360 \mathrm{~cm}$ below either the top of the Brady soil A horizon (if clearly identifiable), or the modern ground surface. Samples for PSA were air-dried, then ground in a mortar and pestle or between two rotating metal plates, using the minimum force required to pass the entire sample through a 2-mm sieve. This allowed thorough homogenization of the samples but eliminated any aggregates $>2 \mathrm{~mm}$. Most particle size data reported here, including all minimally dispersed PSDs, are from high-resolution PSA by laser diffraction, using a Coulter LS100Q instrument, which measures the volume percent of particles in 84 size classes from 0.4 to $984 \mu \mathrm{m}$. The analysis is based upon the average cross-sectional area of particles as they circulate through the measurement cell. The PSD was calculated using the Fraunhofer optical model. Sample preparation and PSA followed one of two protocols:

(1) Minimal dispersion. No pretreatment, dry samples mixed with water and analyzed after circulating in a water suspension $\left(<0.5 \mathrm{~g}\right.$ soil $\left.\mathrm{1}^{-1}\right)$ for $1,4,7$ and $10 \mathrm{~min}$. No somication before or during analysis.

(2) Full dispersion. Samples pretreated prior to analysis, using either sodium acetate buffer $(\mathrm{pH}=5)$ or $10 \% \mathrm{HCl}$ to dissolve carbonates, and warmed $\mathrm{H}_{2} \mathrm{O}_{2}$ to oxidize organic matter. Samples rinsed with deionized water and allowed to settle, and supernatant decanted. Samples then dispersed by shaking overnight in a $0.5 \mathrm{~g}^{-1}$ sodium metaphosphate solution and analyzed in a water suspension, with sonication during analysis.

The effectiveness of the full dispersion procedure was tested by separating the coarse silt and sand from several dispersed samples by sedimentation. Grain mounts were prepared from this coarse fraction, and examined under a petrographic microscope.

The water used to suspend the sample during laser diffraction PSA was "softened" tap water, i.e., divalent and trivalent cations had been replaced by $\mathrm{Na}^{+}$in an exchange column. The $\mathrm{Na}^{+}$concentration in the water was $120-160 \mathrm{ppm}$, and $\mathrm{Ca}^{2+}$ and $\mathrm{Mg}^{2+}$ were $<1$ ppm. This "soft" water was used because it is easier to produce in quantity than deionized water but does not flocculate clay, as ordinary "hard" tap water rich in $\mathrm{Ca}^{2+}$ and $\mathrm{Mg}^{2+}$ might. To test whether water chemistry influenced the degree of aggregation observed in minimally dispersed samples, three samples were analyzed in the standard "soft" water, "hard" tap water, and deionized water.

\subsection{Evaluation of the laser diffraction particle size analysis method}

As a preliminary step in this study, we evaluated the relationship between laser diffraction PSA and traditional methods that are either based directly on settling velocity (pipet method) or have been widely applied in sediment transport studies (sieve analysis). These comparisons have previously been made by Beuselinck et al. (1998) and Buurman 
et al. (1997, 2001), who showed that both the strength and the form of the relationships between methods depends on the type of sediment or soil analyzed.

Laser diffraction senses the average cross-sectional area of particles, rather than effective or Stokes diameter, and the resulting PSD is reported as percentages of total solid volume rather than of total mass. In theory, the most appropriate comparison between methods would be for particles that vary little in density and shape. Therefore, we focused on comparison of laser diffraction and pipet/sieve analyses of fully dispersed samples, because primary particles remaining after dispersion of aggregates are more uniform in density. In total we used 94 samples from unaltered Peoria Loess (C horizon) and the A and B horizons of surface soils formed in Peoria and/or Bignell Loess. Particle size classes measured by laser diffraction were grouped to produce classes comparable with those typically determined by the combined pipet/sieve method. For one set of 71 samples, we compared $\%<2 \mu \mathrm{m}$ and $\%>63 \mu \mathrm{m}$, and for another set of 23 samples we compared $\%$ $<2 \mu \mathrm{m}, \% 2-20 \mu \mathrm{m}$ and $\%>50 \mu \mathrm{m}$.

Relations between laser diffraction and pipet or sieve measurements were linear and relatively strong $\left(R^{2}=0.88-0.97\right)$ although not $1: 1$ (Fig. 2). Relative to the combined pipet/sieve methods, laser diffraction slightly underestimated the content of $>63 \mu \mathrm{m}$ particles, more strongly overestimated the $>50 \mu \mathrm{m}$ and $2-20 \mu \mathrm{m}$ fractions, and greatly
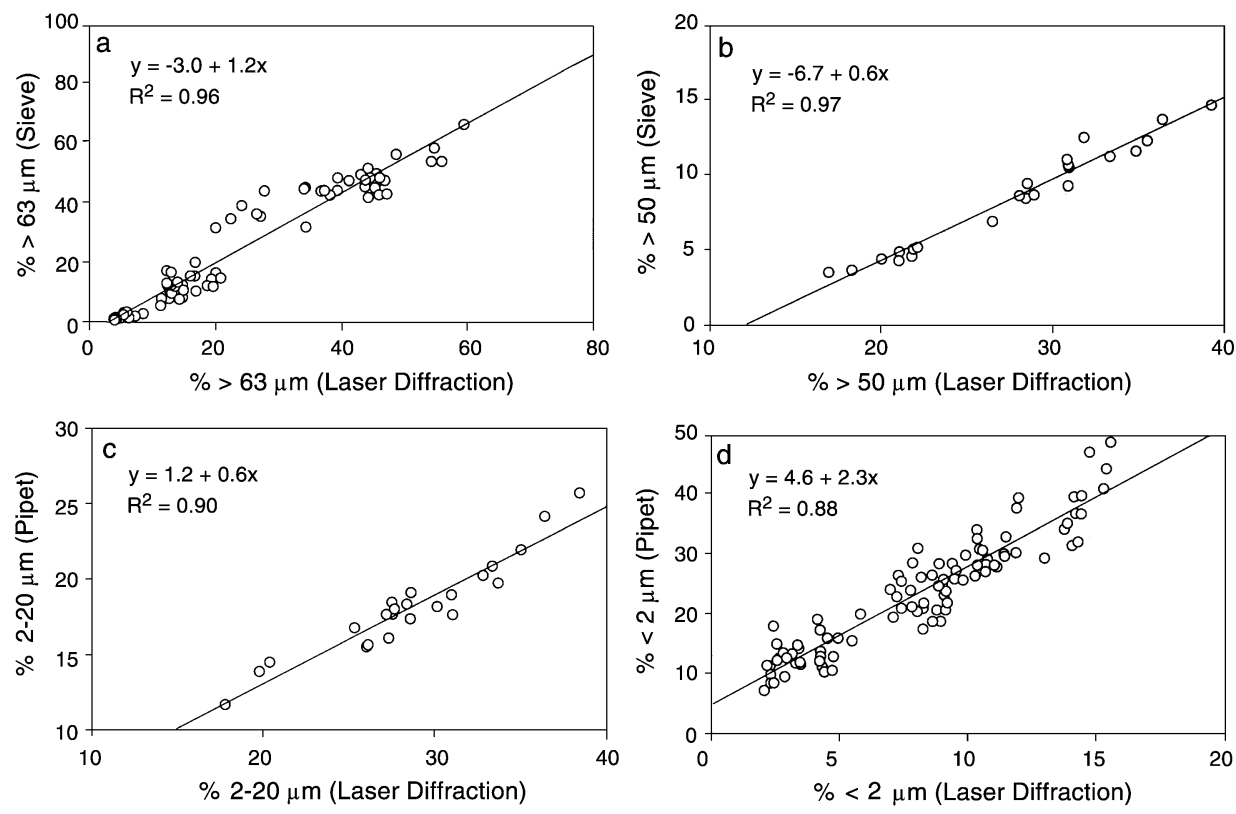

Fig. 2. Relationships between laser diffraction (Coulter LS100Q) and pipet or sieve measurements of selected particle size fractions. Both types of measurements were made on fully dispersed samples, as defined in text. Data shown are from two sets of samples of Nebraska Peoria Loess and soil horizons formed in it; one set of 71 samples was used for (a), another set of 23 samples for (b) and (c), and the two sets were combined for (d). Equations in each panel are best fit least-squares regression models. 
underestimated the $<2 \mu \mathrm{m}$ fraction (Fig. 2). Underestimation of the $\%<2 \mu \mathrm{m}$ was also reported by Beuselinck et al. (1998) and Buurman et al. (2001).

We conclude that, for fully dispersed samples of Nebraska loess, laser diffraction analysis will clearly reproduce the same general particle size contrasts and spatial trends indicated by the pipet/sieve method, although there will be systematic differences in the PSDs produced by the two methods. Thus, laser diffraction data from fully dispersed samples can be used to infer trends related to transport direction, in the same manner as previous studies have used pipet/sieve data. We assume that laser diffraction analysis can also detect transport-related trends in the size of aggregates within minimally dispersed loess samples. We cannot test this directly, however, because our minimally dispersed samples contain not only aggregates but also abundant primary grains that could produce a relatively strong relationship between laser diffraction and pipet/sieve analyses, even if the relationship was weak for aggregates alone. Because of the scatter in the laser diffractionpipet relation for clay (Fig. 2d), we determined clay contents by both pipet (Gee and Bauder, 1986) and laser diffraction for many of the samples.

\section{Results}

\subsection{Thin section observations}

In all thin sections examined, partial or complete coatings were visible on more than $50 \%$ of all medium and coarse silt and sand grains (Fig. 3a). The coatings are mainly oriented clay. There is no discernible difference in grain coating abundance between $\mathrm{C}$ horizon loess and surface soil A and B horizons. In all horizons, coated and uncoated grains appear to be randomly distributed, and we did not observe any concentrations of coated grains within lamellae or other discrete zones. Thus, the clay coatings are unlikely to have resulted from clay illuviation or neoformation associated with development of the surface soil. Instead, the thin section observations suggest that many of the grain coatings were present when the loess was transported, and have persisted since then, even in upper soil horizons.

In all thin sections there were also clearly identifiable, rounded to subangular aggregates of silt and clay that range from about 1000 to $30 \mu \mathrm{m}$ in apparent diameter (Fig. $3 \mathrm{~b}-\mathrm{f}$ ). The largest aggregates, $>250 \mu \mathrm{m}$ in apparent diameter, are especially abundant and well rounded in some A horizons (Fig. 3b), although some aggregates $>250 \mu \mathrm{m}$ were also observed in B and C horizons (Fig. 3c-d). Smaller aggregates are abundant in both A and $\mathrm{C}$ horizons (Fig. 3b-f). We did not attempt to quantify aggregate abundance or PSD in detail by grain counting or image analysis, partly because of the difficulty in distinguishing coalesced or overlapping aggregates. Nonetheless, there is no apparent difference in abundance of finer aggregates between surface soil A horizons and $\mathrm{C}$ horizon loess. Both $\mathrm{A}$ and $\mathrm{C}$ horizons often display patches of spongy microstructure (Bullock et al., 1985) formed by coalescence of aggregates (Fig. 3b-e). Patches with massive microstructure are also present in both $\mathrm{A}$ and $\mathrm{C}$ horizons. Some smaller aggregates $(<100 \mu \mathrm{m})$ in $\mathrm{C}$ horizons do not occur within areas of spongy microstructure; instead they appear to be distributed randomly among primary silt and sand grains (Fig. 3f). Rounded aggregates and spongy 

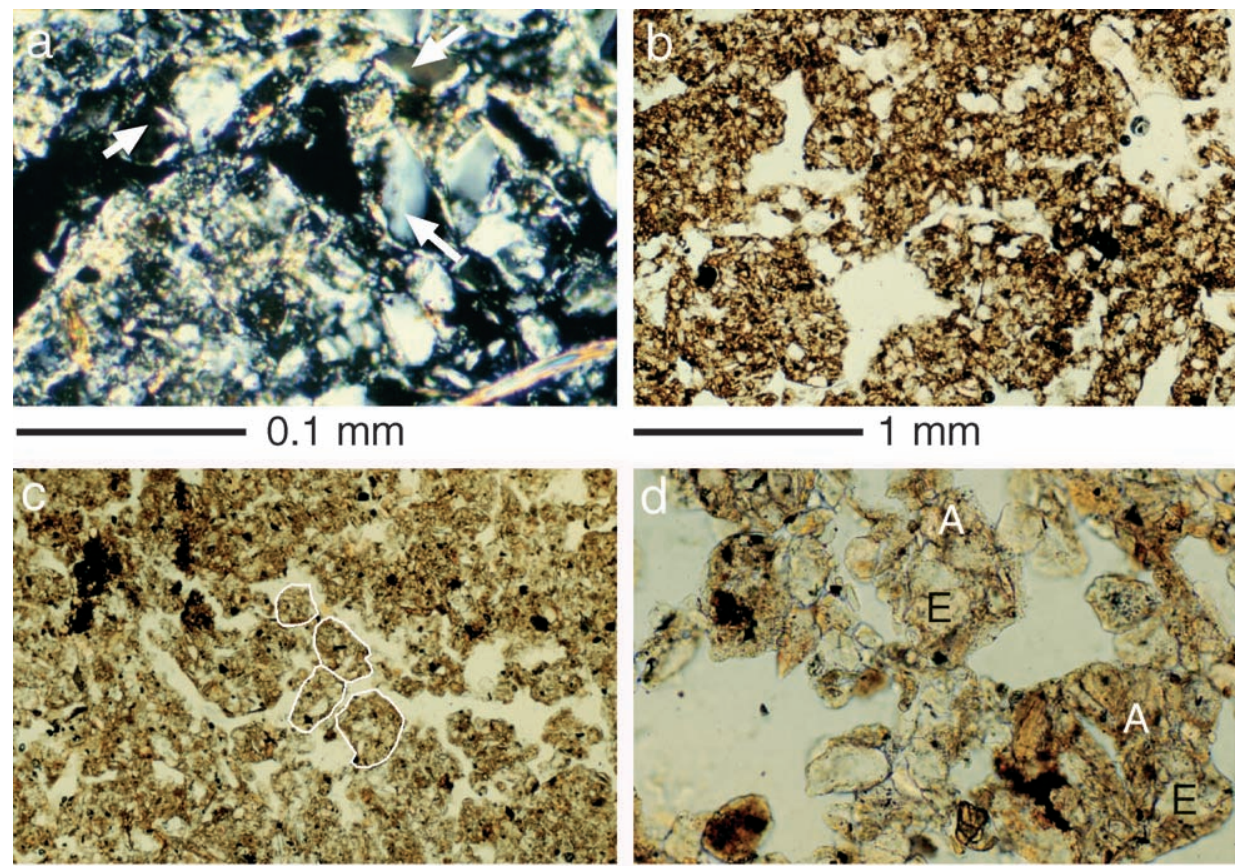

$1 \mathrm{~mm}$

$0.1 \mathrm{~mm}$

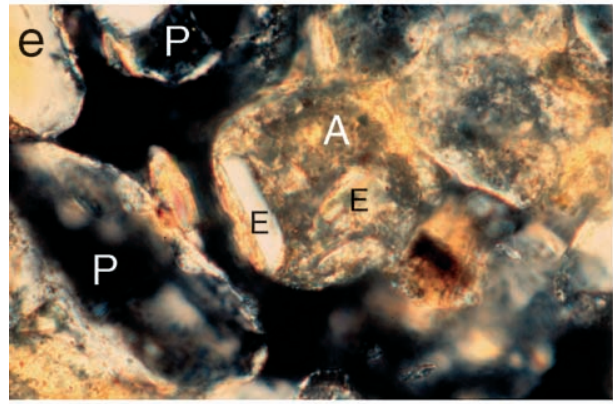

$0.1 \mathrm{~mm}$

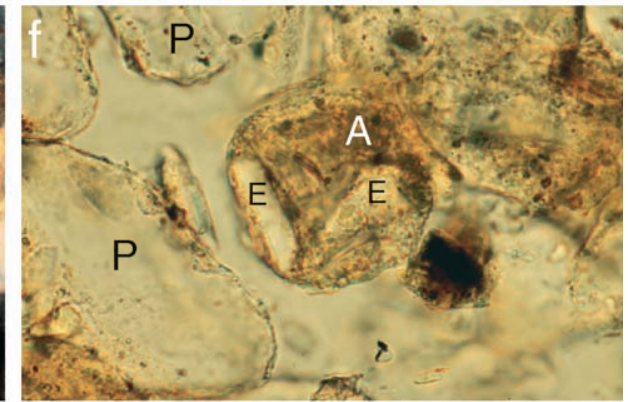

$0.1 \mathrm{~mm}$

Fig. 3. Photomicrographs of $\mathrm{C}$ horizon loess and surface soil horizons, from thin sections of undisturbed core samples $(\mathrm{XPL}=$ cross-polarized light; $\mathrm{PPL}=$ plane-polarized light; depths given are below present land surface): (a) C horizon with abundant coated grains (examples indicated by arrows), site 2G99, $207 \mathrm{~cm}$, XPL; (b) spongy microstructure formed from large, round, partially coalesced aggregates, lower A horizon, site 8G00, $37 \mathrm{~cm}$, PPL; (c) spongy microstructure formed from partially coalesced aggregates, with examples of aggregates outlined in white, C horizon, site 3G98, $220 \mathrm{~cm}$, PPL; (d) relatively large aggregates (labeled A) with embedded silt grains (labeled E), within spongy microstructure in C horizon, site 3G98, $220 \mathrm{~cm}$, PPL; (e) small compact, rounded aggregate (A), surrounded by primary silt grains (P) of similar or slightly smaller size and containing both embedded fine silt grains (E) and oriented clay, C horizon, site 3G98, $360 \mathrm{~cm}$, XPL; (f) same as (e) but PPL.

microstructure are recognizable within larger blocky peds in Bt horizons with $<30 \%$ clay (by pipet). Blocky peds in more clay-rich Bt horizons typically have massive internal microstructure. 
Aggregates of all sizes occur in calcareous and noncalcareous horizons, and no evidence of aggregate cementation by calcite or iron oxides was observed in thin section. In $\mathrm{Bk}$ horizons, secondary carbonate pedofeatures have formed, with $\mathrm{Ca}^{2+}$ supplied by either atmospheric deposition or mineral weathering (a groundwater source is unlikely because in most cases the water table is tens of meters below the Bk horizons). The secondary carbonate partially fills some of the voids between pre-existing rounded aggregates but the aggregates themselves do not contain secondary calcite. Some of the smaller aggregates, particularly those $<100 \mu \mathrm{m}$ in apparent diameter, are mainly composed of oriented clay, but most aggregates in all horizons contain a mixture of clay and embedded fine silt grains (Fig. 3b-f). Some of the aggregates $<100 \mu \mathrm{m}$ are compact (Fig. 3f), but larger aggregates are often more porous and/or partially fragmented (Fig. $3 \mathrm{~b}-\mathrm{d})$.

Rounded aggregates similar in size and morphology to those observed in this study have been reported from soil A horizons, particularly in grassland soils (Pawluk and Bal, 1985; Sanborn and Pawluk, 1989; FitzPatrick, 1993, pp. 124-125). The spongy microstructure formed by coalesced granular aggregates is also commonly observed in nearsurface soil horizons (Pawluk and Bal, 1985; Sanborn and Pawluk, 1989). Granular aggregates in A horizons, including those coalesced into spongy microstructure, have been interpreted most commonly as excrements of soil fauna (Kubiena, 1953; Pawluk and Bal, 1985). These features may also be produced by intense frost action (Pawluk and Bal, 1985) or shrink-swell processes (FitzPatrick, 1993, pp. 124-125) in near-surface horizons. Similar origins are possible for aggregates observed in this study, even though they are abundant in $\mathrm{C}$ horizon loess as well as the surface soil A horizons. Such a vertical distribution is consistent with loess accumulation on a vegetated surface, where the entire column of sediment is at least weakly affected by syndepositional soil faunal activity (Kemp et al., 1996; Kemp, 2001). Occasionally, we found unequivocal evidence for aggregates originating as excrements, where especially well-rounded aggregates filled a faunal burrow, but these observations were rare.

Alternatively, some of the aggregates in our samples could have been transported to the study sites as sedimentary particles. This is especially plausible for finer aggregates slightly larger than surrounding primary grains, because they would have lower densities and therefore similar settling velocities to primary mineral grains of slightly smaller size. Aggregates fine enough to be carried as suspended dust could survive long-distance eolian transport. For example, Greene et al. (1998) found silt and fine sand-sized aggregates of clay and organic matter, which they interpreted as recently deposited dust, on the surface of a native grassland soil in western New South Wales, Australia. Even though there were local dust sources, such as a major river valley and its associated flood plains, most of the dust was probably transported over much larger distances (Greene et al., 2001).

It is unlikely that the larger aggregates $(>250 \mu \mathrm{m})$ observed in our samples were transported by the wind. "Pellet sands" of transported aggregates this large have been reported from loess in central Europe (Kukla, 1975; Frechen et al., 1999), and clay aggregates $>250 \mu \mathrm{m}$ occur in clay dunes (Bowler, 1973), but for most of these there are nearby sediment sources (major river valleys or dry lake beds) from which the large aggregates could have been transported by saltation. Most sand-sized aggregates would probably break up through repeated impacts if transported longer distances by saltation 
(Chepil and Woodruff, 1963). Several of our sites are $>50 \mathrm{~km}$ from the nearest significant loess sources (Mason, 2001), so the larger aggregates at these sites are unlikely to be sedimentary.

In summary, both sedimentary and post-depositional pedogenic origins are plausible for the smaller aggregates observed in thin section. The larger aggregates are most likely postdepositional, so the simplest overall explanation based on thin sections alone would be to interpret all aggregates as the result of near surface faunal activity and other pedogenic processes active as the loess accumulated. However, laser diffraction PSA provides evidence for a sedimentary origin.

\subsection{Particle size distributions of minimally and fully dispersed samples}

Minimally dispersed $\mathrm{C}$ horizon loess samples from all sites yield unimodal distributions dominated by particles $>20 \mu \mathrm{m}$, with a minor "tail" of fine silt and clay (Fig. 4). Except for this fine tail, the distribution is symmetrical to slightly left-skewed.

When a sample is fully dispersed, the mode becomes slightly finer, the fine silt/clay tail becomes a larger "shoulder," and the entire distribution becomes more left-skewed (Fig. 4). The coarsest $C$ horizon samples, dominated by very fine sand, displayed the least change with full dispersion (Fig. 4a). Finer-grained C horizon samples (Fig. 4c and d) displayed a greater shift in the PSD after full dispersion. After conversion to $\phi$ units, the
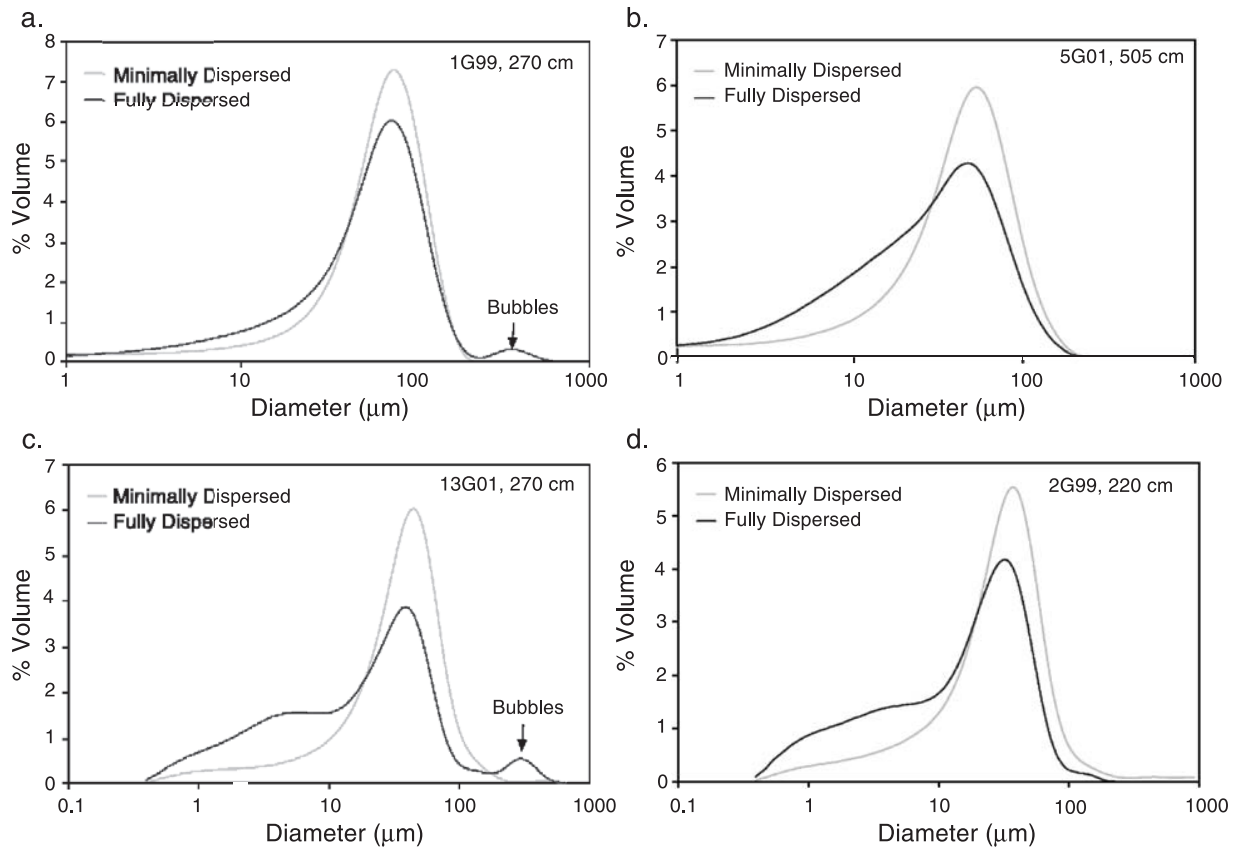

Fig. 4. Examples of paired minimally and fully dispersed PSDs for C horizon loess. Samples are from sites at a range of distances from loess sources, as inferred from thickness trends, with (a) closest to source and (d) farthest (site locations in Fig. 1). Spurious peaks caused by bubbles are indicated; see text for explanation. 
fully dispersed PSDs have sorting values of 1.6-2.1 $\phi$, within the range of typical loess (Pye and Sherwin, 1999). Minimally dispersed PSDs are consistently better sorted, with sorting values of $1.3-1.6 \phi$.

Bubbles occasionally formed in the water-sediment suspension, apparently triggered by sonication during analysis; this produces a spurious $200-400 \mu \mathrm{m}$ peak in the PSD. A $200-400 \mu \mathrm{m}$ peak, representing $<3 \%$ of total volume, appeared in about $30 \%$ of the fully dispersed PSDs (Fig. 4a and c). Because the 200-400 $\mu \mathrm{m}$ peak was of about the same amplitude in all samples analyzed on the same day, including a frequently run standard sample containing no grains $>250 \mu \mathrm{m}$, we believe that it is entirely due to bubbles, and none of our fully dispersed samples actually contain a significant percentage of particles $>250 \mu \mathrm{m}$. None of the minimally dispersed PSDs were affected by bubbles because sonication was not used during analysis of these samples. No minimally dispersed C horizon sample contained more than $1 \%>250 \mu \mathrm{m}$ (some minimally dispersed $\mathrm{Bk}$ and $\mathrm{Bt}$ horizon samples contained aggregates $>250 \mu \mathrm{m}$ that dispersed after a few minutes circulation in the laser diffraction instrument).

These results indicate that the minimally dispersed samples contain aggregates $<250$ $\mu \mathrm{m}$ diameter that are relatively stable in water. These are likely to include at least some of the aggregates $<250 \mu \mathrm{m}$ seen in thin section. Breakdown of these aggregates in fully dispersed samples accounts for the prominent fine shoulder observed in fully dispersed PSDs but not minimally dispersed PSDs. The aggregates $>250 \mu \mathrm{m}$ observed in thin section must break down into primary grains or smaller aggregates in water suspension, even when the minimal dispersion method is used, because minimally dispersed PSDs indicate few particles $>250 \mu \mathrm{m}$. The minor fine-grained tail observed in minimally dispersed PSDs could be in part an artifact introduced by breakdown of aggregates $>250$ $\mu \mathrm{m}$, although it might also reflect mixture of far-traveled dust particles with coarser locally derived loess.

Repeated measurements of the PSD as the water suspension containing minimally dispersed samples circulated in the laser diffraction instrument allowed us to assess the water stability of the aggregates in more detail. The minimally dispersed PSDs of relatively coarse samples changed only slightly over $10 \mathrm{~min}$ of circulation (Fig. 5a). However, finer-grained samples tended to shift over time as the sample circulated, toward a finer mode and slightly larger fine silt and clay shoulder (Fig 5b). Nonetheless, even for the finer-grained samples, the PSD became stable or changed very slowly after 10 min (Fig. 5b). Thus, we used the PSD after 10 min circulation, which includes only relatively stable aggregates, in comparing samples from different sites. The minimally dispersed PSDs of Bt and Bk horizons changed even more than fine-grained $\mathrm{C}$ horizon samples during circulation in the instrument, and did not appear to stabilize even after $10 \mathrm{~min}$ (Fig. 5c). Thus, more advanced pedogenic alteration may have decreased the stability of aggregates in this group of samples, although more detailed studies would be needed to confirm this.

The PSDs of fully dispersed Peoria Loess samples are highly reproducible (Fig. 6), and remain stable regardless of circulation time. Minimally dispersed PSDs are also reproducible when measured after the same circulation time. Analyses of the same sample in "hard" tap water and deionized water produced PSDs similar to those measured in "soft" tap water (the standard method for this study) (Fig. 7). 

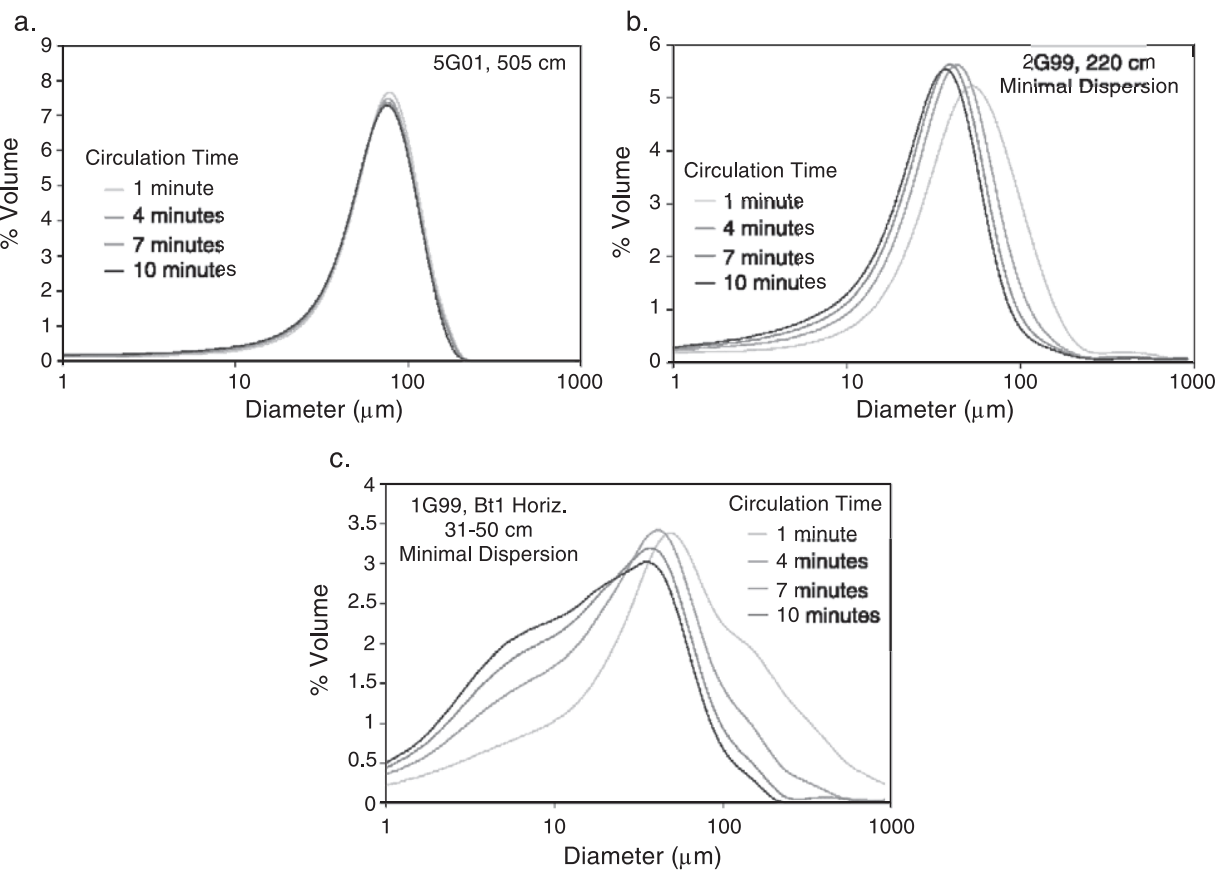

Fig. 5. Sensitivity of minimally dispersed particle size analysis to circulation time in water suspension within the laser diffraction instrument: (a) relatively coarse $\mathrm{C}$ horizon sample; (b) relatively fine $\mathrm{C}$ horizon sample; (c) $\mathrm{Bt}$ horizon sample. Sampling site (Fig. 1) is indicated in each panel.

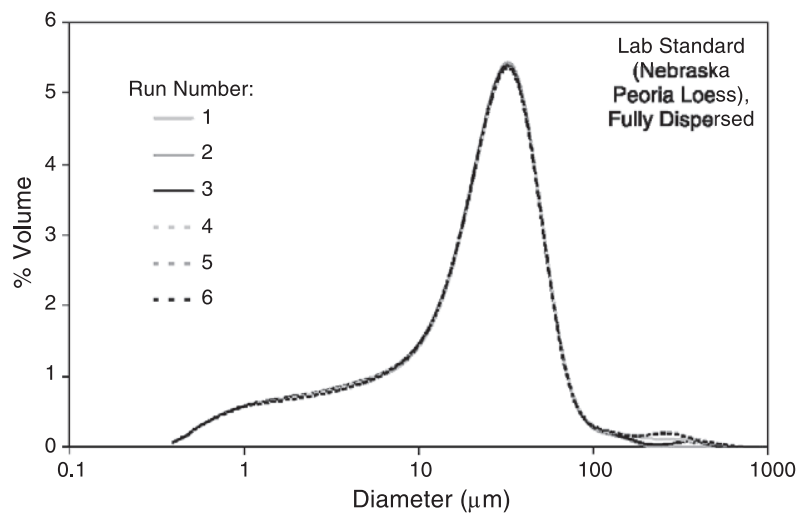

Fig. 6. Example of reproducibility of the fully dispersed PSD, using replicate analyses of laboratory standard (Nebraska Peoria Loess); results are typical of other samples for which the fully dispersed PSA has been replicated. Each PSD shown is from a subsample dispersed and analyzed separately, not from repeat analyses of one sample after dispersion. 


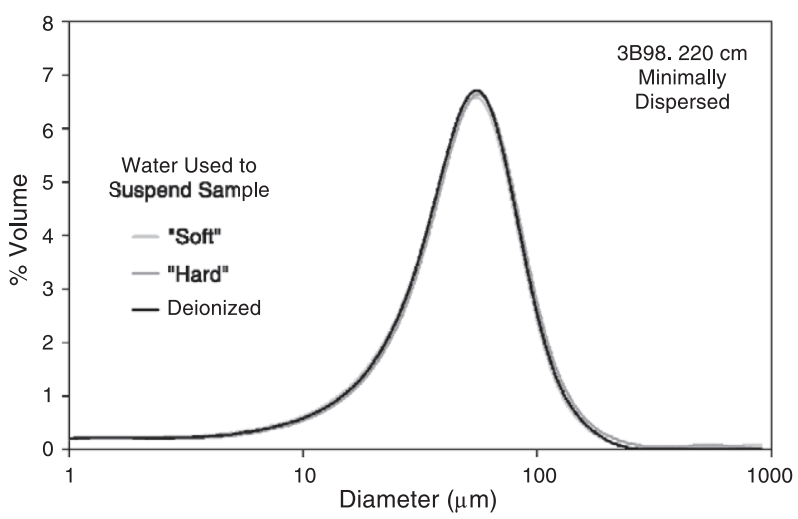

Fig. 7. Example of minimally dispersed PSD analyzed in "soft", "hard", and deionized water.

Grain mounts of coarse silt and very fine sand separated by sedimentation from fully dispersed $\mathrm{C}$ horizon loess samples confirmed that the full dispersion procedure effectively breaks down most aggregates (of all sizes) and thick grain coatings. Based on counts of 400 grains per sample, $\geq 98 \%$ of the sand- or coarse silt-size particles remaining after full dispersion were primary grains. Many of the primary grains have very thin, patchy clay coatings that were not removed by the full dispersion method, but these coatings represented a very small fraction of the total sample volume.

\subsection{Regional trends in abundance and size distribution of aggregates}

Along the three transects, the modal diameters of both minimally and fully dispersed PSDs become finer as the Peoria Loess thins, that is, as distance from its source increases (Fig. 8a and b). To investigate whether the aggregates alone, or all particles in the minimally dispersed PSD, decrease in size with distance from the source, we estimated the modal diameter of water-stable aggregates. For this purpose, we assumed that the
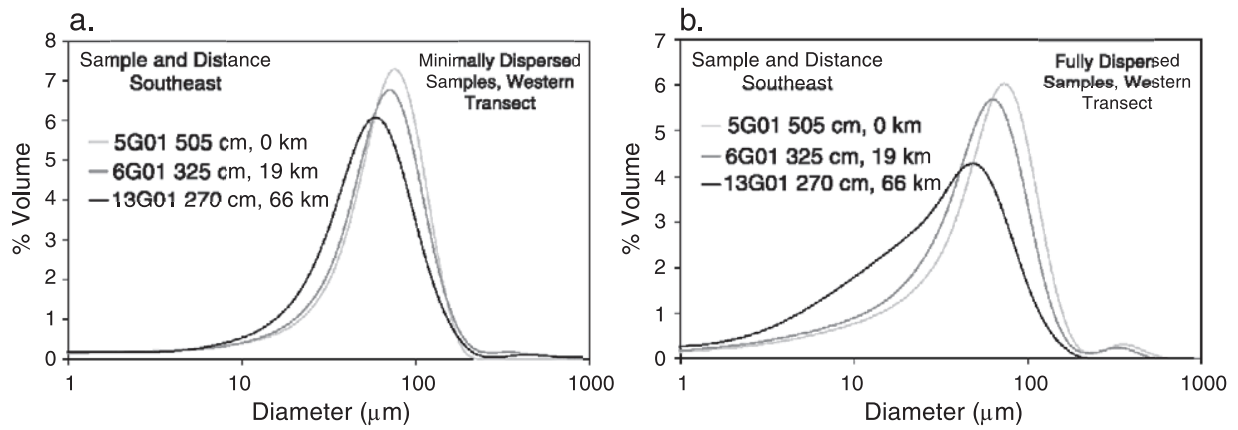

Fig. 8. Shift in (a) minimally dispersed and (b) fully dispersed PSD of C horizon loess, with increasing distance from source. Example shown is Western Transect (Fig. 1); Central and Eastern transects display similar trends. One representative PSD from each site along transect is shown. 
minimally dispersed PSD contains three main components: (1) coarse silt- and sand-sized primary grains (referred to below as coarse primary grains); (2) coarse silt and sand-sized aggregates; and (3) a variable but generally small amount of fine silt and clay, including material produced by breakdown of aggregates that are unstable in water (Fig. 9a). Most coarse primary grains in the minimally dispersed samples probably retain the coatings observed in thin section, but these do not represent a large proportion of the total solid volume. Neglecting the few aggregates that survive vigorous dispersion, we assume that the fully dispersed PSD is a two-component mixture of (1) coarse primary grains; and (2) fine silt and clay, mostly derived from aggregate breakdown (Fig. 9b).

The modal diameter of aggregates can be approximated by the midpoint of the size class corresponding to the maximum positive difference between minimally and fully dispersed PSDs (minimally dispersed minus fully dispersed) (Fig. 9c); this is the size class in which the aggregate component of the minimally dispersed PSD is largest. The aggregate modal diameter estimated in this way is larger than the mode of the fully dispersed PSD for all samples. The true modal diameter of aggregates may lie between the estimated modal diameter and the mode of the minimally dispersed PSD, however. Some primary grains lose coatings in the full dispersion process, and some medium silt grains released from aggregates contribute to the peak of the fully dispersed PSD. Both effects would shift the mode of the fully dispersed PSD toward a finer size than the true mode of
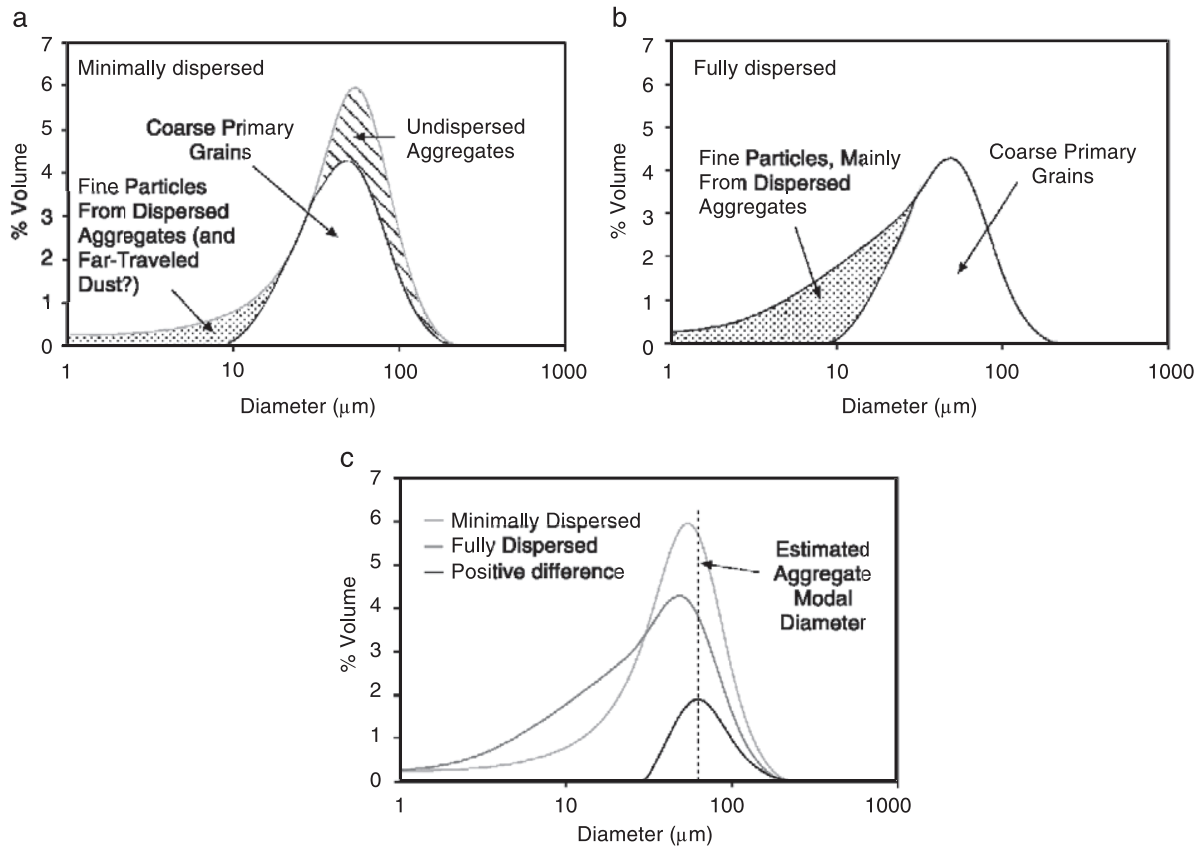

Fig. 9. Conceptual model used to estimate modal diameter of aggregates: (a) three-component model of minimally dispersed PSD; (b) two-component model of fully dispersed PSD; (c) aggregate modal diameter, inferred from maximum of positive difference between PSDs (minimally dispersed minus fully dispersed). See text for more detailed explanation. 
coarse primary grains in the minimally dispersed sample, which in turn will lead to overestimation of the aggregate modal diameter.

Fig. 10 shows that the estimated modal diameter of aggregates decreases with decreasing loess thickness. This trend parallels those for the modes of the minimally and fully dispersed PSDs. All three trends reflect sorting during transport. The minimally dispersed PSD is presumed to reflect most closely the PSD during transport, but there are enough coarse primary grains - transported as single grains - to produce a clear downwind trend in the modes of fully dispersed PSDs. If the aggregates were less dense than the coarse primary grains, aggregates deposited at a given distance from the loess source would have been somewhat larger than coarse primary grains deposited at the same point. This is consistent with the observation that the estimated modal diameter of aggregates is always coarser than the mode of the fully dispersed PSD.

Further evidence for increasing aggregate abundance with distance from the loess source is provided by trends in clay content $(\%<2 \mu \mathrm{m})$. The clay contents of minimally and fully dispersed loess samples analyzed by laser diffraction, and of fully dispersed samples analyzed by pipet, are plotted against Peoria Loess thickness in Fig. 11. For comparison with the pipet measurements, laser diffraction data were converted to pipet values, using the regression equation in Fig. $2 \mathrm{~d}$. The clay content of minimally dispersed samples increases only slightly with decreasing Peoria Loess thickness (from $10 \%$ to $15 \%$

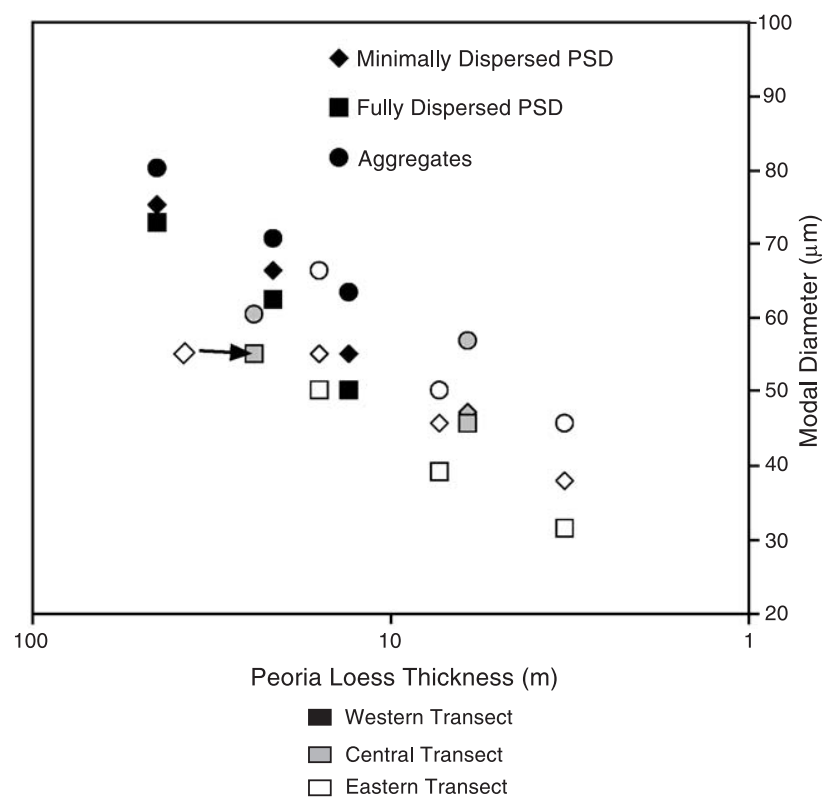

Fig. 10. Variation of modal diameter of minimally and fully dispersed PSDs, and estimated aggregate modal diameter with Peoria Loess thickness. Thickness was measured either at the site or at a nearby test hole in a comparable landscape position. Points represent mean values of $3 \mathrm{C}$ or $\mathrm{BC}$ horizon samples at each sampling site. Three transects are distinguished by different shades of point symbols (see Fig. 1 for site locations). Overlapping symbols are offset for clarity, and the correct position is indicated by an arrow. 


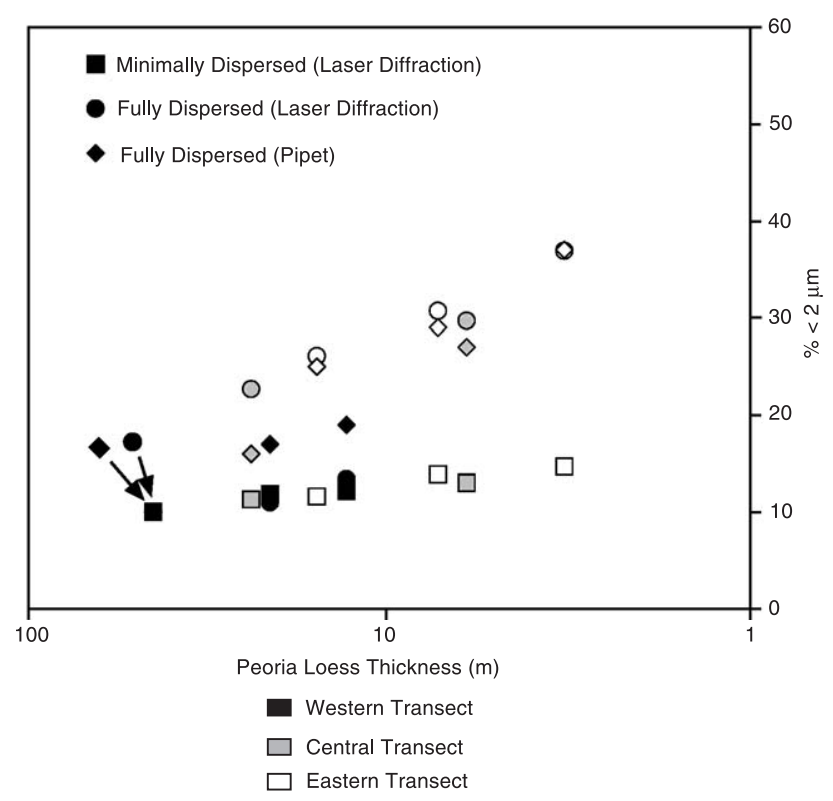

Fig. 11. Variation of clay content $(\%<2 \mu \mathrm{m})$ with Peoria Loess thickness. Clay content was measured on both minimally and fully dispersed samples by laser diffraction, and converted to equivalent pipet clay content using the regression equation shown in Fig. 2d. Clay content measured by pipet on fully dispersed samples is also plotted. Points represent mean values in $\mathrm{C}$ or $\mathrm{BC}$ horizon samples at each sampling site. Thickness was measured either at the site or at a nearby test hole in a comparable landscape position. The three transects are distinguished by different point symbol shades (see Fig. 1 for site locations). Overlapping symbols are offset for clarity (correct positions indicated by arrows).

across the range of thickness), but increases by almost four times (from $10 \%$ to $37 \%$ ) in fully dispersed samples. As the difference between fully and minimally dispersed clay contents represents clay in water-stable aggregates, this suggests that aggregate abundance increases with decreasing loess thickness, that is, with increasing distance from the loess source. Alternatively, aggregates may become more clay-rich with distance downwind, but thin sections indicated no obvious difference in clay content between proximal and distal sites.

\section{Discussion}

\subsection{Aggregates in the Peoria Loess of Nebraska}

The Peoria Loess samples examined here contain aggregates that vary widely in size and also in behavior during particle size analyses. Our results suggest that some of these aggregates were sedimentary particles and others originated by post-depositional pedogenesis. Aggregates $>250 \mu \mathrm{m}$ do not persist in water suspensions, even in the absence of chemical pretreatment or dispersing agents. These aggregates are also too large to have 
been transported tens or hundreds of kilometers from likely loess sources. Based on analogy with pedogenic aggregates described in many other studies, we infer a postdepositional pedogenic origin for aggregates $>250 \mu \mathrm{m}$. Many probably formed as excrements of soil fauna.

Some of the aggregates $<250 \mu \mathrm{m}$ could also have been formed by post-depositional soil faunal activity or other pedogenic processes, but particle size analyses strongly suggest a sedimentary origin for many of the finer aggregates that are stable in water. The estimated modal diameter of water-stable aggregates decreases with decreasing loess thickness and increasing distance from the loess source. We interpret this trend as evidence that the size distribution of the finer, more stable aggregates primarily reflects sorting during transport as suspended dust.

Cementation of aggregates by secondary calcite or iron oxides was not observed in thin section, and apparently is not responsible for the observed stability in water. All aggregates observed in thin section contain a mixture of clay and silt; thus, the clay content of the aggregates may play a key role in their stability. Clay can form very strong compact aggregates when divalent cations are abundant (both on the exchange complex and in the soil solution) and the clay is subjected to extreme wetting and drying cycles (Greene et al., 1978; Quirk, 1994). Perhaps the aggregates that survive minimal dispersion are those that are more compact and/or clay rich.

At least some of the sedimentary aggregates may have been present in the Tertiary rocks that were the ultimate source of much of the loess (Aleinikoff et al., 1998). Some could have formed in sediments derived from those rocks, during extreme wetting and drying cycles on flood plains and lake beds in the loess source region. Similar transported aggregates will not necessarily be present in loess derived primarily from glacial rock flour, for example, along river valleys east of our study area (Grimley, 2000).

The cause of the downwind increase in aggregate abundance is uncertain, but may reflect an upper limit to the size of stable aggregates at the source, so that few of the available aggregates were coarse enough to be deposited at the most proximal sites along with primary sand and silt grains of equivalent settling velocity.

Regardless of the cause, the increase in aggregate abundance with distance from the source provides new insight into trends of loess clay content observed in other studies. Clay content measured in fully dispersed samples increases rapidly with distance from the source along our transects (Fig. 11), and clay increases over similar downwind distances have been observed in loess of other regions (Smith, 1942; Derbyshire et al., 1995; Muhs and Bettis, 2000). However, particles $<2 \mu \mathrm{m}$ have such small settling velocities that they can be transported thousands of kilometers, so their abundance should not increase rapidly over distances $<200 \mathrm{~km}$. In our loess transects, the rapid downwind increase in clay content resulted from a downwind increase in sedimentary aggregate content, as inferred from the difference between minimally and fully dispersed PSDs. The same explanation could also apply to rapid downwind clay increases in other loess-mantled regions.

\subsection{Applicability of minimally dispersed PSA to loess}

This study supports the applicability of minimally dispersed PSA to loess deposits as well as to modern dust samples, for which it was originally proposed (Kiefert et al., 1992; 
McTainsh et al., 1997a,b). As in the modern dust studies, the minimally dispersed PSD is probably a better representation of the effective PSD of the loess during atmospheric transport. However, the occurrence of aggregates in loess does not necessarily render fully dispersed PSDs useless for inferring transport direction or wind speed variation. In Nebraska Peoria Loess, enough primary silt and sand grains were transported and sorted to produce a detectable downwind trend in the mode of fully dispersed PSD, at least when measured by the high resolution laser diffraction method (Fig. 10). On the other hand, our results suggest that the laborious pretreatment required for full dispersion may not be necessary to infer loess transport direction. The modal diameters of the minimally dispersed samples followed exactly the same downwind trend as those of fully dispersed samples, except for a systematic offset that we have explained as the result of aggregation (Fig. 10).

We believe that the combination of minimally and fully dispersed PSA can help resolve problems of loess sedimentology raised by previous research. Muhs et al. (1999) report that the clay content in fully dispersed PSDs of Peoria Loess samples in northeastern Colorado does not increase systematically with distance from the loess sources inferred from other data. Instead, the spatial pattern of loess clay content appears to reflect the availability of clay-rich aggregates from bedrock loess sources. Muhs et al. (1999) ruled out sedimentary sorting as an explanation for the clay content variation, because they had independent evidence of loess transport direction, but such evidence is not always available. Minimally dispersed PSA could be used to test for the presence of clay-rich sedimentary aggregates. As a second example, temporal variation in fully dispersed clay and fine silt content in loess can be interpreted as indicating wind speed variation, or variation in the relative contributions of local and far-traveled dust (e.g. Mason and Jacobs, 1998). Minimally dispersed PSA could be used to test the alternative hypothesis that clay and fine silt variation actually reflects varying aggregate availability at the loess source.

\subsection{Implications for luminescence dating}

At proximal sites (e.g. 5G01 or 3G98, Fig. 1), it is clear that many coarse silt and sand grains were carried as primary particles, and would have been thoroughly exposed to sunlight during transport. Isolation of these coarse grains for luminescence dating should eliminate concerns about inadequate bleaching within aggregates, although grain coatings could still be a problem.

\section{Conclusions}

Thin sections confirmed the presence of aggregates with a wide range of sizes in Peoria Loess samples with little macroscopic evidence of pedogenesis. These aggregates could have resulted from soil faunal activity or other near-surface pedogenic processes after loess deposition, but many of the finer aggregates $(<250 \mu \mathrm{m})$ seem to be sedimentary particles, because they decrease in size with distance from the loess source. We conclude that the Peoria Loess at our study sites includes aggregates that are sedimentary particles, and 
others formed through the post-depositional pedogenesis that affected the slowly accumulating loess.

Our results indicate that high resolution minimally dispersed PSA, previously applied to modern dust (Kiefert et al., 1992; McTainsh et al., 1997a,b), can also help resolve problems of loess sedimentology. This method provided the key evidence for sedimentary aggregates in our study, and in the future should be used to evaluate aggregation as an explanation for spatial or temporal variation in the clay and fine silt content of loess in other regions. On the other hand, traditional fully dispersed PSA can also be used to infer transport direction of the Peoria Loess in Nebraska, and possibly many other loess deposits, because many of the coarse silt and sand grains in the loess were sorted during transport as primary particles.

\section{Acknowledgements}

This research was supported by the National Science Foundation, Geography and Regional Science and Geology and Paleontology Programs (Grants BCS-0079252 and BCS-0079320), the University of Nebraska-Lincoln Research Council, and the Australian National University. We thank W.G. Nickling and E. Derbyshire for helpful reviews, and F.E. Harvey, UNL, for providing water chemistry data.

\section{References}

Aleinikoff, J.N., Muhs, D.R., Fanning, C.M., 1998. Isotopic evidence for the sources of Late Wisconsin (Peoria) Loess, Colorado and Nebraska: implications for paleoclimate. In: Busacca, A.J. (Ed.), Dust Aerosols, Loess Soils, and Global Change. College of Agriculture and Home Economics Miscellaneous Publication MISC0190. Washington State University, Pullman, pp. 124-127.

Beuselinck, L., Govers, G., Poesen, J., Degraer, G., Froyen, L., 1998. Grain-size analysis by laser diffractometry; comparison with the sieve-pipette method. Catena 32, 193-208.

Beuselinck, L., Govers, G., Poesen, J., 1999. Assessment of micro-aggregation using laser diffractometry. Earth Surface Processes and Landforms 24, 41-49.

Bowler, J.M., 1973. Clay dunes; their occurrence, formation and environmental significance. Earth-Science Reviews 9, 315-338.

Brice, J.C., 1966. Erosion and deposition in the loess-mantled Great Plains: Medicine Creek drainage basin, Nebraska. Professional Paper, vol. 352-H. U.S. Geological Survey, Reston, VA.

Bullock, P., Fedoroff, N., Jongerius, A., Stoops, G., Tursina, T., 1985. Handbook for Soil Thin Section Description. Waine Research, Wolverhampton, UK.

Butler, B.E., 1956. Parna, an aeolian clay. Australian Journal of Science 18, 145-151.

Buurman, P., Pape, T., Muggler, C.C., 1997. Laser grain-size determination in soil genetic studies: 1. Practical problems. Soil Science 162, 211-218.

Buurman, P., Pape, T., Reijneveld, J.A., de Jong, J.F., van Gelder, E., 2001. Laser-diffraction and pipette-method grain sizing of Dutch sediments; correlations for fine fractions of marine, fluvial, and loess samples. Geologie en Mijnbouw 80, 49-57.

Chepil, W.S., Woodruff, N.P., 1963. The physics of wind erosion and its control. Advances in Agronomy 15, $211-302$.

Daniels, R.B., 1967. Soil landscapes in the thick loess of central Pottawattamie County, Iowa, landscape evolution and soil formation in southwestern Iowa. Technical Bulletin, vol. 1349. United States, Department of Agriculture, Washington, DC, pp. 205-231. 
Dare-Edwards, A.J., 1984. Aeolian clay deposits of south-eastern Australia; parna or loessic clay? Transactions Institute of British Geographers (New Series) 9, 337-344.

Derbyshire, E., Kemp, R., Meng, X., 1995. Variations in loess and palaeosol properties as indicators of palaeoclimatic gradients across the Loess Plateau of North China. Quaternary Science Reviews 14, 681-697.

FitzPatrick, E.A., 1993. Soil Microscopy and Micromorphology. Wiley, New York.

Frazee, C.J., Fehrenbacher, J.B., Krumbein, W.C., 1970. Loess distribution from a source. Soil Science Society of America Proceedings 34, 296-301.

Frechen, M., Zander, A., Cilek, V., Lozek, V., 1999. Loess chronology of the last interglacial/glacial cycle in Bohemia and Moravia, Czech Republic. Quaternary Science Reviews 18, 1467-1493.

Gee, G.W., Bauder, J.W., 1986. Particle size analysis. In: Klute, A. (Ed.), Methods of Soil Analysis, Part 1. American Society of Agronomy, Madison, WI, pp. 383-411.

Gibbs, H.J., Holland, W.Y., 1960. Petrographic and Engineering Properties of Loess. Engineering Monographs, vol. 28. Bureau of Reclamation, U.S. Department of the Interior, Denver, CO.

Greene, R.S.B., Posner, A.M., Quirk, J.P., 1978. A study of the coagulation of montmorillonite and illite suspensions by calcium chloride using the electron microscope. In: Emerson, W.W., Bond, R.D., Dexter, R.D. (Eds.), Modification of Soil Structure. Wiley, New York, pp. 35-40.

Greene, R.S.B., Nettleton, W.D., Chartres, C.J., Leys, J.F., Cunningham, R.B., 1998. Runoff and micromorphological properties of a grazed Haplargid, near Cobar, NSW, Australia. Australian Journal of Soil Research 36, $87-108$.

Greene, R.S.B., Gatehouse, R., Scott, K.M., Chen, X.Y., 2001. Symposium report: aeolian dust-implications for Australian mineral exploration and environmental management. Australian Journal of Soil Research 39, 1-6.

Grimley, D.A., 2000. Glacial and nonglacial sediment contributions to Wisconsin episode loess in the central United States. Geological Society of America Bulletin 112, 1475-1495.

Johnson, W.C., Willey, K.L., 2000. Isotopic and rock magnetic expression of environmental changes at the Pleistocene-Holocene transition in the central Great Plains. Quaternary International 67, 89-106.

Kemp, R.A., 2001. Pedogenic modification of loess; significance for palaeoclimatic reconstructions. Earth Science Reviews 54, $145-156$.

Kemp, R.A., Derbyshire, E., Chen, F., Ma, H., 1996. Pedosedimentary development and palaeoenvironmental significance of the S1 palaeosol on the northeastern margin of the Qinghai-Xizang (Tibetan) Plateau. Journal of Quaternary Science 11, 95-106.

Kiefert, L., McTainsh, G.H., Nickling, W.G., 1992. Pretreatment techniques for particle-size analysis of dust samples from high volume sampler filter papers. Journal of Sedimentary Petrology 62, 729-731.

Kubiena, W.L., 1953. The Soils of Europe. Murby, London.

Kukla, G.J., 1975. Loess stratigraphy of central Europe. In: Butzer, K.W., Isaac, G.L. (Eds.), After the Australopithecines; Stratigraphy, Ecology, and Culture Change in the Middle Pleistocene. Mouton Publ., The Hague, pp. 99-188.

Kuzila, M.S., 1995. Identification of multiple loess units within modern soils of Clay County, Nebraska. Geoderma $65,45-57$.

Kwaad, F.J.P.M., Muecher, H.J., 1994. Degradation of soil structure by welding - a micromorphological study. Catena 23, 253-268.

Lian, O.B., Huntley, D.J., 1999. Optical dating studies of postglacial aeolian deposits from the south-central interior of British Columbia, Canada. Quaternary Science Reviews 18, 1453-1466.

Lu, H., van Huissteden, K., An, Z., Nugteren, G., Vandenberghe, J., 1999. East Asia winter monsoon variations on a millennial time-scale before the last glacial-interglacial cycle. Journal of Quaternary Science 14, 101-110.

Mason, J.A., 2001. Transport direction of Peoria Loess in Nebraska and implications for loess sources on the central Great Plains. Quaternary Research 56, 79-86.

Mason, J.A., Jacobs, P.M., 1998. Chemical and particle-size evidence for addition of fine dust to soils of the Midwestern United States. Geology 26, 1135-1138.

Mason, J.A., Nater, E.A., Hobbs, H.C., 1994. Transport direction of Wisconsinan loess in southeastern Minnesota. Quaternary Research 41, 44-51.

McTainsh, G., 1999. Dust transport and deposition. In: Goudie, A.S., Livingstone, I., Stokes, S. (Eds.), Aeolian Environments, Sediments and Landforms. Wiley, Chichester, pp. 181-211. 
McTainsh, G.H., Lynch, A.W., Hales, R., 1997a. Particle-size analysis of aeolian dusts, soils and sediments in very small quantities using a Coulter Multisizer. Earth Surface Processes and Landforms 22, 1207-1216.

McTainsh, G.H., Nickling, W.G., Lynch, A.W., 1997b. Dust deposition and particle size in Mali, West Africa. Catena 29, 307-322.

Muhs, D.R., Bettis III, E.A., 2000. Geochemical variations in Peoria Loess of western Iowa indicate paleowinds of midcontinental North America during last glaciation. Quaternary Research 53, 49-61.

Muhs, D.R., Aleinikoff, J.N., Stafford Jr., T.W., Kihl, R., Been, J., Mahan, S.A., Cowherd, S., 1999. Late Quaternary loess in northeastern Colorado: Part I. Age and paleoclimatic significance. Geological Society of America Bulletin 111, $1861-1875$.

Nicholas, A.P., Walling, D.E., 1996. The significance of particle aggregation in the overbank deposition of suspended sediment on river floodplains. Journal of Hydrology 186, 277-295.

Pawluk, S., Bal, L., 1985. Micromorphology of selected mollic epipedons. In: Douglas, L.A., Thompson, M.L. (Eds.), Soil Micromorphology and Soil Classification. SSSA Special Publications, vol. 15. Soil Science Society of America, Madison, pp. 63-83.

Pye, K., Sherwin, D., 1999. Loess. In: Goudie, A.S., Livingstone, I., Stokes, S. (Eds.), Aeolian Environments, Sediments and Landforms. Wiley, Chichester, pp. 213-238.

Quirk, J.P., 1994. Interparticle forces: a basis for the interpretation of soil physical behaviour. Advances in Agronomy 53, 121-183.

Ruhe, R.V., 1983. Depositional environment of late Wisconsin loess in the Midcontinental United States. In: Porter, S.C. (Ed.), The Late Pleistocene. Univ. Minn. Press, Minneapolis, pp. 130-137.

Sanborn, P., Pawluk, S., 1989. Microstructural diversity in Ah horizons of Black Chernozemic soils, Alberta and British Columbia. Geoderma 45, 221-240.

Schultz, C.B., Stout, T.M., 1945. Pleistocene loess deposits of Nebraska. American Journal of Science 243, $231-244$.

Slattery, M.C., Burt, T.P., 1995. Size characteristics of sediment eroded from agricultural soil; dispersed versus non-dispersed, ultimate versus effective. In: Hickin, E.J. (Ed.), River Geomorphology. Wiley, Chichester, pp. $1-17$.

Smith, G.D., 1942. Illinois loess; variations in its properties and distribution, a pedologic interpretation. University of Illinois Experiment Station Bulletin 490, 139-184. 